\title{
Validity of immunohistochemistry method in predicting $H E R-2$ gene status and association of clinicopathological variables with it in invasive breast cancer patients
}

\section{MOHAMMAD KAZZEM GHEYBI, ${ }^{1}$ AZAR BARADARAN,${ }^{2}$ MOHAMMAD REZA MOHAJERI,${ }^{3}$ AFSHIN OSTOVAR, ${ }^{4}$ PARVANEH HAJALIKHANI ${ }^{5}$ and SHOKROLLAH FARROKHI ${ }^{6}$}

${ }^{1}$ Persian Gulf Tropical Medicine Research Centre, Bushehr University of Medical Sciences, Bushehr; ${ }^{2}$ Department of Pathology, Isfahan University of Medical Sciences; ${ }^{3}$ Dr. Mohajeri Laboratory of Isfahan, Isfahan; ${ }^{4}$ Department of Epidemiology, Persian Gulf Tropical Medicine Research Centre, Bushehr University of Medical Sciences, Bushehr; ${ }^{5}$ School of Medicine, Isfahan University of Medical Sciences, Isfahan; and

${ }^{6}$ Department of Immunology, Persian Gulf Tropical Medicine Research Center, Bushehr University of Medical Sciences, Bushehr, Iran

Gheybi MK, Baradaran A, Mohajeri MR, Ostovar A, Hajalikhani P, Farrokhi S. Validity of immunohistochemistry method in predicting HER-2 gene status and association of clinicopathological variables with it in invasive breast cancer patients. APMIS 2016; 124: 365-371.

Human epidermal growth factor receptor-2 is an important and prognostic factors and one of the most targeted proteins in breast cancer's therapy. There is no globally accepted method for determining its status. Here, we aimed to evaluate the immunohistochemistry method validity in predicting $H E R-2$ status by Fluorescence in situ hybridization method and investigate some clinicopathological variables association with HER-2 amplification. A total of 190 HER-2 $2+$ and $3+$ by immunohistochemistry (IHC) invasive breast cancer cases were enrolled in this study. Fluorescence in situ hybridization (FISH) was performed for these cases using FDA criteria and the association between clinicopathological variables and HER-2 status evaluated. Study consisted of 190 invasive breast cancer patients (160 HER-2 2+ and 30 HER-2 3+). HER-2 FISH amplification according to FDA criteria was found $27.5 \%$ (44/160 patients) in HER-2 2+ patients and $83.3 \%$ (25/30 patients) in HER-2 3+ patients. Tumors with HER-2 amplification were more likely to be ER-negative $(51.0 \%$ vs $31.2 \%, \mathrm{p}=0.013)$ and PR-negative $(52.9 \%$ vs $27.0 \%, \mathrm{p}<0.001)$. This study showed that immunohistochemistry is not a good method for evaluating HER-2 status and decision-making about trastuzumab therapy even with $3+$ score patients. However, this result may not be too strong for IHC $3+$ cases due to the limited number of these patients in this study.

Key words: Invasive breast cancer; human epidermal growth factor receptor-2; immunohistochemistry; fluorescent in situ hybridization; prediction.

Mohammad Kazzem Gheybi, Persian Gulf Tropical Medicine Research Centre, Bushehr University of Medical Sciences, Bushehr, Postal code: 7514633341, Iran. e-mail: Kazzem7@yahoo.com

Breast cancer is responsible for $28 \%$ of the newly diagnosed cancer cases in women worldwide and second leading cause of cancer death in human (1, 2). Breast cancer with HER-2 overexpression currently comprises $15-20 \%$ of all cases in the world (3). HER-2/neu, located on chromosome $17 \mathrm{q} 21$, encodes for the $185-\mathrm{kD}$ transmembrane glycopro-

Received 6 December 2015. Accepted 21 December 2015 tein $H E R-2 \mathrm{CA}$, which is one of the most targeted proteins and plays a role in cell growth, differentiation, adhesion, motility, and signal conduction (4). HER-2 amplification or overexpression has been demonstrated to be an independent parameter for bad prognosis. Even adjuvant hormonal therapy is not sufficient for these patients with positive estrogen receptors $(5,6)$.

HER-2-targeted therapies have significantly improved disease-free survival in women with 
HER-2-positive cancers both in early and metastatic breast cancer $(7,8)$. Three HER-2-targeted agents, trastuzumab (Herceptin), lapatinib (Tykerb), and pertuzumab (Perjeta), have been made available in the past decade for the treatment of HER-2-positive metastatic breast cancer (9). The importance of precise detection of HER-2 amplification is cleared with knowing the difficulties imposed by a 1-year course of treatment with Herceptin; this drug carries a substantial financial burden and perhaps, more importantly, introduces the risk of cardiotoxicity (10-12).

The US Food and Drug Administration (FDA) approved methodologies include the assessment of the protein level by immunohistochemistry (IHC) or gene copy count on the DNA level by in situ hybridization technology (ISH) $(13,14)$. Fluorescence in situ hybridization (FISH) is considered the gold standard for evaluating HER-2 status, which has become essential in the era of personalized cancer therapy $(13,15)$. IHC is the most frequently used as initial laboratory test for HER-2 protein expression, because it is convenient and inexpensive. HER-2 IHC results are generally divided into four scale scores (range, $0-3+$ ) on the basis of percentage of positive tumor cells and staining intensity. The US Food and Drug Administration (FDA) and American Society of Clinical Oncology/ College of American Pathologists (ASCO/CAPs) recommends that HER-2 IHC scores of 0 and $1+$ should be regarded as HER-2 negative and those with HER-2 3+ scores should be considered HER-2 positive. Tumors that show strong circumferential staining in $<10 \%$ of tumor cells or incomplete and/ or weak/moderate staining of $>10 \%$ of the invasive tumor cells are categorized IHC $2+$ score and are regarded as HER-2 equivocal and should be further assessed by FISH $(16,17)$.

The aims of the study were to evaluate the accuracy of immunohistochemistry as a method for predicting HER-2 gene amplification status in a series of patients with IHC HER-2 2+, 3+ breast cancer and to study associations between HER-2 status and clinicopathological factors.

\section{MATERIALS AND METHODS}

\section{Patients}

In this study we enrolled 190 patients diagnosed with invasive breast cancer including 160 HER-2 $2+$ and 30 HER-2 3+ in Alzahra hospital of Isfahan from March 2012 to August 2014. All patients were newly confirmed for invasive breast cancer status and have not received treatment. The patients and participants signed approved institutional review board consent forms before inclusion in the study. Patient clinical history and tumor characteristics were obtained from histopathology reports and medical records. Gathered data included age histological grade, tumor size, regional lymph node status, lymphovascular invasion, estrogen receptor (ER), progesterone receptor (PR), and HER-2 status. Nottingham criteria used to describe histological grade $(18,19)$. The tumor extent was measured by TNM staging according to the new staging system of the American Joint Committee on Cancer/International Union against Cancer (AJCC/UICC) (20). This study was approved by research and ethics committee of Isfahan University of medical sciences.

\section{Immunohistochemistry}

Human epidermal growth factor receptor-2 IHC stains were performed with the HercepTest according to the manufacturer's instructions: the HercepTest (DAKO, Glostrup, Denmark). Each IHC stain was run with the kit control slides according to the manufacturers' instructions. Briefly, 4- $\mu \mathrm{m}$-thick mounted sections on slides from formaldehyde-fixed paraffin-embedded tissue blocks were deparaffinizad by xylene solution for $5 \mathrm{~min}$ and rehydrated in graded alcohols for 3 min. After deparaffinization, tissue sections were placed in $0.1 \mathrm{M}$ sodium citrate buffer (PH 6) for $40 \mathrm{~min}$ at $99{ }^{\circ} \mathrm{C}$, after which the antigen was retrieved. The slides were then incubated with prediluted anti-HER2 antibody for $1 \mathrm{~h}$. After incubation, the sections were washed in PBS and incubated with horseradish peroxidase-conjugated secondary antibody. Color development was performed using 3,3'-diaminobenzidine, and the tissue samples were counterstained with hematoxylin. Negative and positive control slides were included in each assay. Samples were interpreted according to the ASCO/CAP guidelines: negative $(0,1+)$, weakly positive $(2+)$, and strongly positive $(3+)$. The results were interpreted by two independent pathologists.

All cases also underwent immunochemistry for hormone receptors. Primary antibodies used were mouse monoclonal anti-human ER antibody (1D5, Dako, Glostrup, Denmark) and mouse monoclonal anti-human progesterone receptor (PgR636, Glostrup, Denmark) antibody. A cutoff level of $10 \%$ or greater was defined as positive for ER and PR expression.

\section{FISH}

The Cytocell HER-2 probe kit (LPS 001; Aquarius, Cytocell Technologies, Cambridge, UK) was used to analyze samples by FISH according to the supplier's instructions. First, the sections were baked overnight. Following deparaffinization by xylene, the slides were dehydrated and air-dried. The enzyme was freshly prepared by dilution. After protease digestion for $18 \mathrm{~min}$, the slides and probes for HER-2 and the centromere of chromosome 17 (internal control) were treated at $72{ }^{\circ} \mathrm{C}$ for $2 \mathrm{~min}$ in denaturation solution simultaneously. The probes and target DNA were hybridized in a humidified chamber at $37{ }^{\circ} \mathrm{C}$ overnight. The slides were washed with Post-hybridization wash buffer by $0.4 \times \mathrm{SSC}$ at $72{ }^{\circ} \mathrm{C}$ for $2 \mathrm{~min}$ and once with $2 \times \mathrm{SSC}$ at room temperature for 30 seconds and counterstained with 4,6-diamidino-2-phenylindole. The number of chromosome 17 and HER-2 signals were scored for 20 tumor cell nuclei in the invasive tumor region which had been previously marked by the pathologist. HER-2 gene status was evaluated based on the ratio 
of HER-2 signals and chromosome 17 centromic signals. A mean CEP17 signals per nucleus of $\geq 3$ was considered as polysomy 17 (21). The FISH specimens were analyzed on a Nikon Eclipse 80i fluorescence microscope (Nikon Corp, Tokyo, Japan) with special filters. In our study, a case was regarded HER-2 gene amplified if the ratio of $H E R-2 / C E P 17$ was equal to or more than 2.0 as FDA recommendation.

\section{Statistical analysis}

Pearson's chi-square test was performed to evaluate the association between clinicopathological variables and HER-2 FISH positivity. Student's t-test was used to compare age between the HER-2 negative and positive groups. Probability values $<5 \%$ were considered statistically significant.

For showing influence of risk factors on HER-2 status (dependent variable) we used logistic regression model. In order to choose variables to involve in logistic regression, variables entered in logistic regression with $H E R-2$ status one by one and crude OR noted. After that variables with $\mathrm{p}$ value $\leq 0.2$ considered for final multivariable logistic regression model.

All statistical analysis were performed using the PASW Gradpack 21 (SPSS Inc. Chicago, IL, USA).

\section{RESULTS}

This study consisted of 190 invasive breast cancer patients (160 HER-2 2+ and 30 HER-2 3+). Study population median age was 48.63 years (range, 2777 years). Histhopathological grade was available In 135 patients $(71.0 \%) .90$ patients $(47.3 \%)$ were grade 1 or 2 and 45 patients $(25.2 \%)$ were grade 3 . Hormone receptor (HR) status was available in all patients. ER was expressed in 141 patients $(74.2 \%)$. PR also was expressed in 122 patients $(64.2 \%)$. Hundred and twelve patients $(58.9 \%)$ were ER and PR positive and 10 patients $(5.2 \%)$ were ER negative and PR positive. Lymphovascular invasion (LVI) was seen in $45.7 \%$ ( 87 patients). The tumor size $(\mathrm{T})$ and regional lymph node status $(\mathrm{N})$ are shown in Table 1.

HER-2 FISH amplification according to FDA criteria was found $27.5 \%$ (44/160 patients) in HER$22+$ patients and $83.3 \%$ (25/30 patients) in HER-2 $3+$ patients. Totally 69 patients $(36.3 \%)$ were HER2 FISH amplified (Table 1).

No significant differences existed between HER-2 positive and HER-2 negative groups with respect to

Table 1. Distribution of HER-2 FISH results in IHC 2+ and $3+$ breast cancer patients based on FDA guidelines

\begin{tabular}{lrllr}
\hline & & FISH negative (\%) & FISH positive $(\%)$ & Total \\
\hline IHC & $2+$ & $116(72.5)$ & $44(27.5)$ & 160 \\
& $3+$ & $5(16.7)$ & $25(83.3)$ & 30 \\
\multicolumn{2}{l}{ Total } & $121(63.7)$ & $69(36.3)$ & 190 \\
\hline
\end{tabular}

age (48.82 years vs 48.52 years, $\mathrm{p}=0.854)$, cancer location $(\mathrm{p}=0.108)$, lymphovascular invasion $(\mathrm{p}=0.303)$ or increased chromosome 17 copy number $(\mathrm{p}=0.493)$. Patients with HER-2 FISH amplification tumors were not likely to have higher histological grades $(p=0.371)$ compared with patients with unamplified tumors. Tumors with HER-2 amplification were more likely to be ERnegative $(51.0 \%$ vs $31.2 \%, \mathrm{p}=0.013)$ and $\mathrm{PR}-$ negative $(52.9 \%$ vs $27.0 \%, \mathrm{p}<0.001)$ (Table 2$)$.

A logistic regression model was used to reveal risk factors for $H E R-2$ amplification. The purpose of this logistic regression is to discover the impact of each clinicopathological variable on HER-2 amplification singly; considering that other variables may affect the target variable's result. The association between clinicopathological variables and HER-2 amplification is shown in Table 3. Tumor location, $\mathrm{T}$ stage, $\mathrm{N}$ stage, ER status, and PR status entered in final logistic regression model. Subjects with ER-positive expressions were less likely to exhibit HER-2 amplification compared

Table 2. correlation of HER-2 FISH results with clinicopathological variables in 190 breast cancer patients (significant $\mathrm{P}$ values are shown bold)

\begin{tabular}{|c|c|c|c|}
\hline & $\begin{array}{l}\text { HER-2 } \\
\text { negative } \\
\text { n }(\%)\end{array}$ & $\begin{array}{l}\text { HER-2 } \\
\text { positive } \\
\mathrm{n}(\%)\end{array}$ & $\mathrm{p}$ \\
\hline Patients & $121(63.7)$ & $69(36.3)$ & \\
\hline Age & 48.82 & 48.52 & 0.854 \\
\hline \multicolumn{4}{|l|}{ Location } \\
\hline Left & $52(57.8)$ & $38(42.2)$ & \multirow[t]{2}{*}{0.108} \\
\hline Right & 69 (69) & $31(31)$ & \\
\hline \multicolumn{4}{|l|}{ Histological grade } \\
\hline $1-2$ & $61(67.8)$ & $29(32.2)$ & \multirow[t]{3}{*}{0.371} \\
\hline 3 & $27(60)$ & $18(40)$ & \\
\hline Not evaluable & $33(60)$ & $22(40)$ & \\
\hline \multicolumn{4}{|l|}{ T stage } \\
\hline 1 & $25(71.4)$ & $10(28.6)$ & \multirow[t]{4}{*}{0.224} \\
\hline 2 & $86(64.7)$ & $47(35.3)$ & \\
\hline 3 & $8(44.4)$ & $10(55.6)$ & \\
\hline 4 & $2(50)$ & $2(50)$ & \\
\hline \multicolumn{4}{|l|}{$\mathrm{N}$ stage } \\
\hline 0 & $53(69.7)$ & $23(30.3)$ & \multirow[t]{4}{*}{0.329} \\
\hline 1 & $41(64)$ & $23(36)$ & \\
\hline 2 & $16(51.6)$ & $15(48.4)$ & \\
\hline 3 & $11(57.9)$ & $8(42.1)$ & \\
\hline \multicolumn{4}{|l|}{ LVI } \\
\hline Negative & $69(67.0)$ & $34(33.0)$ & \multirow[t]{2}{*}{0.303} \\
\hline Positive & $52(59.8)$ & $35(40.2)$ & \\
\hline \multicolumn{4}{|l|}{ ER status } \\
\hline Negative & 24 (48.9) & $25(51.1)$ & \multirow[t]{2}{*}{0.013} \\
\hline Positive & $97(68.7)$ & $44(31.3)$ & \\
\hline \multicolumn{4}{|l|}{ PR status } \\
\hline Negative & $32(47.2)$ & $36(52.9)$ & \multirow[t]{2}{*}{$<0.001$} \\
\hline Positive & $89(73.0)$ & $33(27.0)$ & \\
\hline \multicolumn{4}{|l|}{ Polysomy 17} \\
\hline Negative & $98(64.9)$ & $53(35.1)$ & \multirow[t]{2}{*}{0.493} \\
\hline Positive & $23(59.0)$ & $16(41.0)$ & \\
\hline
\end{tabular}


Table 3. Logistic regression analysis of risk factors for HER-2 FISH positive in 190 breast cancer patients (In all variables, first condition is supposed as reference) (significant $\mathrm{P}$ values are shown bold)

\begin{tabular}{lllll}
\hline & & OR & $95 \%$ CI & $\mathrm{p}$ \\
\hline Age group & Crude & 1.12 & $0.62-2.02$ & 0.711 \\
$(<50, \geq 50)$ & Adjusted & - & - & - \\
Location & Crude & 0.62 & $0.34-1.12$ & $\mathbf{0 . 1 0 9}$ \\
(Left, Right) & Adjusted & 0.76 & $0.25-2.32$ & 0.639 \\
Histological grade & Crude & 1.40 & $0.67-2.95$ & 0.372 \\
$(1-2,3)$ & Adjusted & - & - & - \\
T stage & Crude & 1.58 & $0.95-2.62$ & $\mathbf{0 . 0 7 2}$ \\
(T1, T2-3-4) & Adjusted & 1.63 & $0.96-2.77$ & 0.067 \\
N stage & Crude & 1.28 & $0.94-1.72$ & $\mathbf{0 . 1 0 7}$ \\
(N0, N1-2-3) & Adjusted & 0.64 & $0.32-1.28$ & 0.215 \\
LVI & Crude & 1.37 & $0.76-2.47$ & 0.303 \\
(negative, positive) & Adjusted & - & - & - \\
ER status & Crude & 0.44 & $0.22-0.85$ & $\mathbf{0 . 0 1 4}$ \\
(negative, positive) & Adjusted & 0.24 & $0.07-0.87$ & $\mathbf{0 . 0 3 0}$ \\
PR status & Crude & 0.33 & $0.18-0.61$ & $<\mathbf{0 . 0 0 1}$ \\
(negative, positive) & Adjusted & 0.32 & $0.14-0.74$ & $\mathbf{0 . 0 0 8}$ \\
\hline
\end{tabular}

Table 4. HER-2 gene amplification in IHC $2+$ and $3+$ breast cancer patients with Polysomy 17 (mean CEP17 signals per nucleus of $\geq 3$ )

\begin{tabular}{lclll}
\hline & & FISH negative $(\%)$ & FISH positive $(\%)$ & Total \\
\hline IHC & $2+$ & $22(62.9)$ & $13(37.1)$ & 35 \\
& $3+$ & $1(25)$ & $3(75)$ & 4 \\
\multicolumn{1}{l}{ Total } & $23(59.0)$ & $16(41.0)$ & 39 \\
\hline
\end{tabular}

with those with ER-negative expression $(\mathrm{OR}=0.24 ; 95 \% \mathrm{CI}=0.07-0.87 ; \mathrm{p}=0.030)$. The risk was also reduced in cases with PR-positive expressions than those with PR-negative expressions $(\mathrm{OR}=0.32 ; 95 \% \mathrm{CI}=0.14-0.74 ; \mathrm{p}=0.008)$.

There was polysomy 17 in $39(20.5 \%)$ patients of which $35(21.8 \%)$ and $4(13.3 \%)$ cases were IHC $2+$, and IHC $3+$ respectively (Table 4 ).

\section{DISCUSSION}

Human epidermal growth factor receptor-2, has been widely accepted as a prognostic and predictive marker in the management and treatment of breast cancer (22). Using trastuzumab supplement for neoadjuvant or adjuvant chemotherapy provides significant survival benefit in invasive breast cancer with $H E R$-2-overexpressing tumor cells. However, for HER-2-negative cases, with any IHC score, trastuzumab offers no benefit and only contributes cardiotoxicity and waste of money $(16,17)$. The high cost and side effects of trastuzumab therapy demand that highly accurate, robust, sensitive, and cost-effective testing protocols be used in clinical settings $(16,23)$. The best method to evaluate HER-2 status of breast cancer is still debated among pathologists. Because each technique has its own advantages and disadvantages, a standard screening tool has not yet been determined. Several studies have proposed IHC as the first line screening method for HER-2 status $(15,24)$. IHC staining is easy to perform and relatively inexpensive as a method for evaluating $H E R-2$ status. However, there is a wide range of inter- and intra-laboratory variation in its sensitivity and specificity $(25,26)$. Factors such as tissue fixation (and its impact on HER-2 protein antigenicity), the scoring method, and the choice of antibody may contribute to a lower specificity and sensitivity of $\operatorname{IHC}(23,27)$. Based on a recent study, false results could be decreased by standardization of these pre-analytic steps of IHC (28). Cases with weak positive staining (2+) by HER-2 IHC represent a subgroup of patients that requires additional assessment with FISH. Applying updated $\mathrm{ASCO} / \mathrm{CAP}$ recommendations would improve overall accuracy of HER2 testing due to the widening of IHC $2+$ cases (28). Some researchers have previously studied the probability of HER-2 2+ IHC breast cancers for HER-2 amplification (17). In a study which was also in Iranian population $36 \%$ of HER-2 2+ samples were HER-2 amplified (23). Another study with a relatively large population of 1735 breast cancer $H E R-2$ amplification were seen in $14 \%$ of patients (29). Other studies have also reported 30-35\% HER-2 amplification among IHC samples $2+$ score $(30,31)$.

Numerous previous studies have reported that HER-2 overexpression (IHC $3+$ ) or HER-2 amplification is associated with high tumor cell grade, absence of ER or PR expression, DNA aneuploidy, and high Ki-67 $(32,33)$. Many studies also investigated factors which could predict HER-2 amplification in breast cancer patients. In a study which assessed correlation of different risk factors with HER-2 amplification in IHC $2+$ breast cancer patients, ER and PR positivity were shown to be related with negative $H E R-2$ status and better prognosis (17).

In our study, we integrated clinical and pathological factors from 190 breast cancer cases with IHC score of $2+$ and $3+$. All samples were routinely submitted for FISH analysis to determine the HER-2 gene status. We found that $27.5 \%(44 / 160)$ of IHC $2+$ cases were HER-2 amplified. Which was a lower percentage in comparison with most of other studies. The reason is probably the fact that in the new ASCO/CAP HER2 testing recommendation update used in this study, the IHC 2+ "equivocal" category has been expanded to include cases that would have previously been classified as $1+$ negative or 0 negative (3). Positive correlation was also found between HR and HER-2 status agreeing with previous studies. We expected to see higher tumor size ( $\mathrm{T}$ stage) and regional lymph node involvement 
(N stage) in HER-2-amplified patients, but they did not have significant association. However, $T$ stage was very close to have a relation with HER-2 positivity based on our results $(p=0.067)$. Higher tumor grade and lymph node invasion also had no association with $H E R-2$ amplification. We also found five cases with IHC 3+ score to be HER-2 negative on FISH. Based on established literature data it can be assumed that the way and duration of antigen retrieval and fixation can lead to inconsistent and incorrect IHC results (34). FISH assay is less prone to fixation and laboratory errors than IHC tests, making FISH assay more reproducible if signal interpretation is carried out by experienced pathologists. However, many studies stated that HER-2 IHC false positive cases still benefit from adjuvant trastuzumab therapy (35).

Polysomy 17 is common among invasive breast cancer patients, however, the exact effect of polysomy 17 on HER-2 amplification remains controversial (21). Some studies have reported that breast cancer patients with polysomy 17 respond to trastuzumab therapy independently of $H E R-2$ amplification (36), however, other researchers believe that polysomy 17 patients without $H E R-2$ amplification do not benefit from anti HER-2 agents (13). Prevalence of polysomy 17 is reported in the range of 3$46 \%$ using the definition of $\geq 3$ CEP per cell (37). In this study polysomy 17 was seen in $20.5 \%$ of patients. Also polysomy 17 is reported to be more common in IHC $2+$ cases which agrees the findings of our study (38).

Some limitations were observed in this study. First we did not include Ki-67 and p-53 in breast cancer risk factors while many studies did show that they can predict HER-2 status. The other limitation was few numbers of patients, especially IHC $3+$ cases which was due to the FDA criteria to perform FISH for IHC $2+$ patients only. Our IHC $3+$ cases which FISH was performed for them were those who had a relative contraindication for Herceptin therapy like patients with high blood pressure or heart failure; Therefore these patients may not be representative of $\mathrm{IHC}+3$ patients in general. In a recently meta-analysis, HER- 2 IHC $0 / 1+$ and $3+$ cannot be absolutely considered as negative and positive (39). In our study results also $16.7 \%(5 / 30)$ of patients with $3+\mathrm{IHC}$ score were not HER-2 amplified which confirmed this fact.

In conclusion, IHC can not be the best method for evaluating $H E R-2$ amplification in breast cancer patients even in patients with $3+$ score. Studying alternative methods for detecting HER-2 amplification should be considered. Researches with larger groups and more predicting risk factors must perform in different populations.
Thanks to Isfahan Alzahra hospital laboratory and Dr. Mohajeri laboratory of Isfahan staff for their helpful assistance. Special thanks to Dr. Zohreh Naimi, Dr. Shirin Sadeghpour and Dr. Saeed Tajbakhsh for their kind support.

\section{REFERENCES}

1. Siegel R, Naishadham D, Jemal A. Cancer statistics, 2013. CA Cancer J Clin 2013;63:11-30.

2. Babu GR, Samari G, Cohen SP, Mahapatra T, wahbe $\mathrm{RM}$, Mermash $\mathrm{S}$, et al. Breast cancer screening among females in Iran and recommendations for improved practice: a review. Asian Pac J Cancer Prev 2011;12:1647-55.

3. Wolff AC, Hammond ME, Hicks DG, Dowsett M, McShane LM, Allison $\mathrm{KH}$, et al. Recommendations for human epidermal growth factor receptor 2 testing in breast cancer: American Society of Clinical Oncology/College of American Pathologists clinical practice guideline update. J Clin Oncol 2013;31:3997-4013.

4. Ithimakin S, Day KC, Malik F, Zen Q, Dawsey SJ, Bersano-Begey TF, et al. HER2 drives luminal breast cancer stem cells in the absence of HER2 amplification: implications for efficacy of adjuvant trastuzumab. Cancer Res 2013;73:1635-46.

5. Freedman OC, Fletcher GG, Gandhi S, Mates M, Dent $\mathrm{SF}$, Trudeau ME, et al. Adjuvant endocrine therapy for early breast cancer: a systematic review of the evidence for the 2014 Cancer Care Ontario systemic therapy guideline. Curr Oncol 2015;22(Suppl 1):S95-113.

6. Hurvitz SA, Hu Y, O'Brien N, Finn RS. Current approaches and future directions in the treatment of HER2-positive breast cancer. Cancer Treat Rev 2013;39:219-29.

7. Nielsen DL, Kumler I, Palshof JA, Andersson M. Efficacy of HER2-targeted therapy in metastatic breast cancer. Monoclonal antibodies and tyrosine kinase inhibitors. Breast 2013;22:1-12.

8. Davoli A, Hocevar BA, Brown TL. Progression and treatment of HER2-positive breast cancer. Cancer Chemother Pharmacol 2010;65:611-23.

9. Jelovac D, Emens LA. HER2-directed therapy for metastatic breast cancer. Oncology (Williston Park) 2013;27:166-75.

10. Keyhani E, Muhammadnejad A, Karimlou M. Prevalence of HER-2-positive invasive breast cancer: a systematic review from Iran. Asian Pac J Cancer Prev 2012;13:5477-82.

11. Criscitiello C, Curigliano G. HER2 signaling pathway and trastuzumab cardiotoxicity. Future Oncol 2013;9:179-81.

12. Farolfi A, Melegari E, Aquilina M, Scarpi E, Ibrahim $\mathrm{T}$, Maltoni R, et al. Trastuzumab-induced cardiotoxicity in early breast cancer patients: a retrospective study of possible risk and protective factors. Heart 2013;99:634-9.

13. Moelans CB, de Weger RA, Van der Wall E, van Diest PJ. Current technologies for HER2 testing in breast cancer. Crit Rev Oncol Hematol 2011;80:380-92.

14. Dekker TJ, Smit VT, Hooijer GK, Van de Vijver MJ, Mesker WE, Tollenaar RA, et al. Reliability of core 
needle biopsy for determining ER and HER2 status in breast cancer. Ann Oncol 2013;24:931-7.

15. Yoon N, Do IG, Cho EY. Analysis of HER2 status in breast carcinoma by fully automated HER2 fluorescence in situ hybridization (FISH): comparison of two immunohistochemical tests and manual FISH. APMIS 2014;122:755-60.

16. Rakha EA, Starczynski J, Lee AH, Ellis IO. The updated ASCO/CAP guideline recommendations for HER2 testing in the management of invasive breast cancer: a critical review of their implications for routine practice. Histopathology 2014;64: 609-15.

17. Ji Y, Sheng L, Du X, Qiu G, Chen B, Wang X. Clinicopathological variables predicting HER-2 gene status in immunohistochemistry-equivocal (2+) invasive breast cancer. J Thorac Dis 2014;6:896-904.

18. Elston CW, Ellis IO. Pathological prognostic factors in breast cancer. I. The value of histological grade in breast cancer: experience from a large study with long-term follow-up. Histopathology 1991;19:403-10.

19. Rakha EA, Reis-Filho JS, Baehner F, Dabbs DJ, Decker $\mathrm{T}$, Eusebi V, et al. Breast cancer prognostic classification in the molecular era: the role of histological grade. Breast Cancer Res 2010;12:207.

20. Murthy V, Chamberlain RS. Further expansion of the AJCC/UICC breast cancer staging system to encompass unique problems in the developing world. Ann Surg Oncol 2011;18(Suppl 3):S278-80.

21. Zhu X, Lu Y, Lu H, Yang W, Tu X, Cai X, et al. Genetic alterations and protein expression of HER2 and chromosome 17 polysomy in breast cancer. Hum Pathol 2011;42:1499-504.

22. Rosa FE, Silveira SM, Silveira CG, Bergamo NA, Neto FA, Domingues MA, et al. Quantitative realtime RT-PCR and chromogenic in situ hybridization: precise methods to detect HER-2 status in breast carcinoma. BMC Cancer 2009;9:90.

23. Pazhoomand R, Keyhani E, Banan M, Najmabadi H, Khodadadi F, Iraniparast A, et al. Detection of HER2 status in breast cancer: comparison of current methods with MLPA and real-time RT-PCR. Asian Pac J Cancer Prev 2013;14:7621-8.

24. Dietel M, Ellis IO, Hofler H, Kreipe H, Moch H, Dankof A, et al. Comparison of automated silver enhanced in situ hybridisation (SISH) and fluorescence ISH (FISH) for the validation of HER2 gene status in breast carcinoma according to the guidelines of the American Society of Clinical Oncology and the College of American Pathologists. Virchows Arch 2007:451:19-25.

25. Vanden Bempt I, Vanhentenrijk V, Drijkoningen M, Wlodarska I, Vandenberghe P, De Wolf-Peeters C. Real-time reverse transcription-PCR and fluorescence in-situ hybridization are complementary to understand the mechanisms involved in HER-2/neu overexpression in human breast carcinomas. Histopathology 2005;46:431-41.

26. Press MF, Sauter G, Bernstein L, Villalobos IE, Mirlacher M, Zhou JY, et al. Diagnostic evaluation of HER-2 as a molecular target: an assessment of accuracy and reproducibility of laboratory testing in large, prospective, randomized clinical trials. Clin Cancer Res 2005;11:6598-607.
27. Carlsson J, Nordgren H, Sjostrom J, Wester K, Villman $\mathrm{K}$, Bengtsson NO, et al. HER2 expression in breast cancer primary tumours and corresponding metastases. Original data and literature review. $\mathrm{Br} \mathbf{J}$ Cancer 2004;90:2344-8.

28. Bianchi S, Caini S, Paglierani M, Saieva C, Vezzosi $\mathrm{V}$, Baroni $\mathrm{G}$, et al. Accuracy and reproducibility of HER2 status in breast cancer using immunohistochemistry: a quality control study in Tuscany evaluating the impact of updated 2013 ASCO/ CAP recommendations. Pathol Oncol Res 2015;21: 477-85.

29. Lee AH, Key HP, Bell JA, Hodi Z, Ellis IO. Breast carcinomas with borderline (2+) HER2 immunohistochemistry: percentage of cells with complete membrane staining for HER2 and the frequency of HER2 amplification. J Clin Pathol 2011;64:490-2.

30. Chibon F, de Mascarel I, Sierankowski G, Brouste $\mathrm{V}$, Bonnefoi $\mathrm{H}$, Debled $\mathrm{M}$, et al. Prediction of HER2 gene status in Her2 2+ invasive breast cancer: a study of 108 cases comparing ASCO/CAP and FDA recommendations. Mod Pathol 2009;22: 403-9.

31. Dieci MV, Barbieri E, Bettelli S, Piacentini F, Omarini C, Ficarra G, et al. Predictors of human epidermal growth factor receptor 2 fluorescence in-situ hybridisation amplification in immunohistochemistry score $2+$ infiltrating breast cancer: a single institution analysis. J Clin Pathol 2012;65:503-6.

32. Liu C, Zhang H, Shuang C, Lu Y, Jin F, Xu H, et al. Alterations of ER, PR, HER-2/neu, and P53 protein expression in ductal breast carcinomas and clinical implications. Med Oncol 2010;27:747-52.

33. Hanley K, Wang J, Bourne P, Yang Q, Gao AC, Lyman $\mathrm{G}$, et al. Lack of expression of androgen receptor may play a critical role in transformation from in situ to invasive basal subtype of high-grade ductal carcinoma of the breast. Hum Pathol 2008;39:386-92.

34. Varga Z, Noske A, Ramach C, Padberg B, Moch H. Assessment of HER2 status in breast cancer: overall positivity rate and accuracy by fluorescence in situ hybridization and immunohistochemistry in a single institution over 12 years: a quality control study. BMC Cancer 2013;13:615.

35. Nitta H, Kelly BD, Padilla M, Wick N, Brunhoeber $\mathrm{P}$, Bai I, et al. A gene-protein assay for human epidermal growth factor receptor 2 (HER2): brightfield tricolor visualization of HER2 protein, the HER2 gene, and chromosome 17 centromere (CEN17) in formalinfixed, paraffin-embedded breast cancer tissue sections. Diagn Pathol 2012;7:60.

36. Hofmann M, Stoss O, Gaiser T, Kneitz H, Heinmöller $\mathrm{P}$, Gutjahr T, et al. Central HER2 IHC and FISH analysis in a trastuzumab (Herceptin) phase II monotherapy study: assessment of test sensitivity and impact of chromosome 17 polysomy. J Clin Pathol 2008;61:89-94.

37. Hanna WM, Ruschoff J, Bilous M, Coudry RA, Dowsett M, Osamura RY, et al. HER2 in situ hybridization in breast cancer: clinical implications of polysomy 17 and genetic heterogeneity. Mod Pathol 2014;27:4-18.

38. Pu X, Shi J, Li Z, Feng A, Ye Q. Comparison of the 2007 and 2013 ASCO/CAP evaluation systems for 


\section{HER-2; VALIDITY OF IHC AND ASSOCIATIONS}

HER2 amplification in breast cancer. Pathol Res Pract 2015;211:421-5.

39. Bahreini F, Soltanian AR, Mehdipour P. A meta-analysis on concordance between immunohistochemistry
(IHC) and fluorescence in situ hybridization (FISH) to detect HER2 gene overexpression in breast cancer. Breast Cancer 2014;22:615-625. 